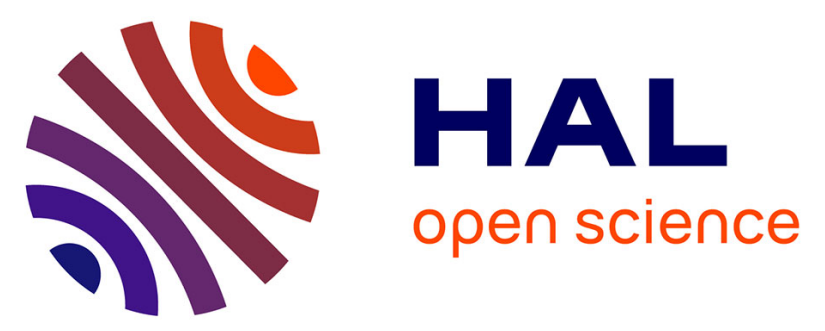

\title{
Preoperative staging of liver metastases from uveal melanoma by magnetic resonance imaging (MRI) and fluorodeoxyglucose-positron emission tomography (FDG-PET)
}

\author{
V. Servois, P. Mariani, C. Malhaire, S. Petras, S. Piperno-Neumann, C. \\ Plancher, C. Levy-Gabriel, L. Lumbroso-Le Rouic, L. Desjardins, R.J. Salmon
}

\section{To cite this version:}

V. Servois, P. Mariani, C. Malhaire, S. Petras, S. Piperno-Neumann, et al.. Preoperative staging of liver metastases from uveal melanoma by magnetic resonance imaging (MRI) and fluorodeoxyglucosepositron emission tomography (FDG-PET). EJSO - European Journal of Surgical Oncology, 2010, 36

(2), pp.189. 10.1016/j.ejso.2009.08.010 . hal-00557766

\section{HAL Id: hal-00557766 \\ https://hal.science/hal-00557766}

Submitted on 20 Jan 2011

HAL is a multi-disciplinary open access archive for the deposit and dissemination of scientific research documents, whether they are published or not. The documents may come from teaching and research institutions in France or abroad, or from public or private research centers.
L'archive ouverte pluridisciplinaire HAL, est destinée au dépôt et à la diffusion de documents scientifiques de niveau recherche, publiés ou non, émanant des établissements d'enseignement et de recherche français ou étrangers, des laboratoires publics ou privés. 


\section{Accepted Manuscript}

Title: Preoperative staging of liver metastases from uveal melanoma by magnetic resonance imaging (MRI) and fluorodeoxyglucose-positron emission tomography (FDG-PET)

Authors: V. Servois, P. Mariani, C. Malhaire, S. Petras, S. Piperno-Neumann, C.

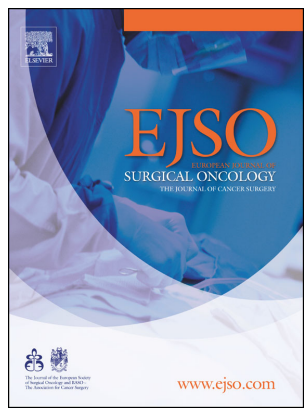
Plancher, C. Levy-Gabriel, L. Lumbroso-Le Rouic, L. Desjardins, R.J. Salmon

PII:

$$
\text { S0748-7983(09)00442-9 }
$$

DOI:

$$
\text { 10.1016/j.ejso.2009.08.010 }
$$

Reference: $\quad$ YEJSO 2885

To appear in: European Journal of Surgical Oncology

Received Date: 17 June 2009

Revised Date: 18 August 2009

Accepted Date: 23 August 2009

Please cite this article as: Servois V, Mariani P, Malhaire C, Petras S, Piperno-Neumann S, Plancher C, Levy-Gabriel C, Lumbroso-Le Rouic L, Desjardins L, Salmon RJ. Preoperative staging of liver metastases from uveal melanoma by magnetic resonance imaging (MRI) and fluorodeoxyglucosepositron emission tomography (FDG-PET), European Journal of Surgical Oncology (2009), doi: 10.1016/ j.ejso.2009.08.010

This is a PDF file of an unedited manuscript that has been accepted for publication. As a service to our customers we are providing this early version of the manuscript. The manuscript will undergo copyediting, typesetting, and review of the resulting proof before it is published in its final form. Please note that during the production process errors may be discovered which could affect the content, and all legal disclaimers that apply to the journal pertain. 
Preoperative staging of liver metastases from uveal melanoma by magnetic resonance imaging (MRI) and fluorodeoxyglucose-positron emission tomography (FDG-PET).

V. Servois ${ }^{\text {a }}$, P. Mariani ${ }^{\text {b*, }}$ C. Malhaire ${ }^{\text {a }}$, S. Petras ${ }^{\text {a }}$, S. Piperno-Neumann ${ }^{\text {c }}$, C. Plancher ${ }^{\text { }}$, C. Levy-Gabriel $^{\text {b }}$, L Lumbroso-le Rouic ${ }^{\text {b }}$, L. Desjardins ${ }^{\text {b }}$, R.J. Salmon ${ }^{\text {b }}$.

${ }^{\text {a }}$ Department of Radiology and Nuclear Medicine, Institut Curie, 26 rue d’Ulm, 75248 Paris

Cedex 05, France

${ }^{\mathrm{b}}$ Department of Surgery, Institut Curie, Paris, France

${ }^{\mathrm{c}}$ Department of Medical Oncology, Institut Curie, Paris, France

${ }^{\mathrm{d}}$ Department of Statistics, Institut Curie, Paris, France

${ }^{*}$ Corresponding author and reprints: P.Mariani

Tel : +144324645

Fax : +1 53104037

e-mail: pascale.mariani@curie.net 


\begin{abstract}
Background: Microscopically complete (R0) resection of metastases from uveal melanoma prolongs median overall survival compared to incomplete surgery. The aim of this study was to compare the sensitivity of dynamic-enhanced magnetic resonance imaging (MRI) with fluorodeoxyglucose-positron emission tomography (FDG-PET) in the preoperative diagnosis of liver metastases from uveal melanoma.

Patients and methods: Fifteen consecutive patients (mean age: 56 years) underwent FDGPET and liver MRI. Extrahepatic metastatic disease was excluded by whole body computed tomography and bone scintigraphy. MRI and FDG-PET were performed with a mean of 19 days (range: 1-30) before surgery. Imaging findings were compared with surgical (including intraoperative ultrasonography) and histological findings on a lesion by lesion analysis.

Results: R0 resection was performed in 12 patients. A total of 28 lesions were resected with 27 histologically proven metastases. Nine lesions were smaller than $5 \mathrm{~mm}, 7$ measured $5-10$ $\mathrm{mm}$ and 11 were larger than $10 \mathrm{~mm}$. Sensitivity and positive predictive value were $67 \%$ and 95\% for MRI compared to $41 \%$ and $100 \%$ for FDG-PET. The difference between the two modalities was statistically significant ( $p=0.01$; McNemar test). In remaining 3 patients, diffuse miliary disease ( $>10$ capsular lesions) was discovered intraoperatively, and was suspected on preoperative MRI in 2 cases. Only one extrahepatic lesion identified by FDGPET was falsely positive.

Conclusions: In this preliminary study, MRI was superior to FDG-PET for staging of liver metastases from uveal melanoma. Although miliary disease was suggested by MRI in some cases, preoperative confirmation remains imperfect.
\end{abstract}

Key-words : uveal melanoma, liver metastase, liver magnetic resonance imaging, fluorodeoxyglucose-positron emission tomography. 


\section{Introduction}

Uveal melanoma is the most frequent primary malignant intraocular tumour in adults; 500 to 600 new cases are diagnosed each year in France. ${ }^{1}$ Metastatic spread of uveal melanoma is observed in $50 \%$ of patients and the liver is the almost exclusive site of metastases after a mean interval of 3 years. $^{2}$ The recommended hepatic surveillance after treatment of intraocular tumour comprises liver ultrasound (US), every 6 months for 10 years and liver computed tomography (CT) scan and/or liver magnetic resonance imaging (MRI) when an abnormality is detected on liver ultrasound. Following the detection of metastases, the median overall survival without treatment ranges from 2 to 6 months according to the study. ${ }^{3}$ The early diagnosis of liver metastases may allow R0 (microscopically complete) surgical resection in patients with limited metastatic extension. In the experience reported by the Institut Curie in 1998, based on 75 operated patients, survival was 22 months in the case of $\mathrm{R} 0$ resection versus 9 months in the case of $\mathrm{R} 1$ or $\mathrm{R} 2$ incomplete resection. ${ }^{4}$ These data were updated in 2009 in a series of 224 patients confirming a complete resection rate of $28 \%$ and a median survival of 22 months for R0 resected patients (13 months for the overall cohort). ${ }^{5}$ The main limitation to R0 surgery is the intraoperative discovery of miliary liver metastases that makes R0 resection impossible.

Liver imaging methods classically comprise US, CT , MRI and F[18] fluoro-desoxyglucose (FDG) positron emission tomography (FDG-PET). MRI is the investigation technique of choice, as it presents a sensitivity of detection at least equivalent to that of computed tomography with better specificity. ${ }^{6}$ In the particular diagnosis of uveal melanoma, the presence of melanin in metastatic lesions induces shortening of $\mathrm{T} 1$ and $\mathrm{T} 2$ relaxation times. ${ }^{7,8}$ Typical lesions therefore have a high-intensity appearance on T1-weighted sequences. The hypervascular nature of most metastatic lesions also allows improved detection and characterization of abnormalities on T1-weighted dynamic sequences after injection of a gadolinium chelate.

Although FDG-PET has been evaluated in the metastatic staging of cutaneous malignant melanoma. ${ }^{9,10}$ Few studies have evaluated FDG-PET in uveal melanoma. ${ }^{11-13}$ This whole body imaging modality presents the theoretical advantage of evaluating liver involvement while also detecting any extrahepatic one. To our knowledge, no study has compared the contribution of MRI and FDG-PET in the preoperative assessment of liver metastases from uveal melanoma. 
The objective of this study was therefore to compare the performances of MRI and FDG-PET in the preoperative assessment of liver metastases from uveal melanoma by comparing them with intraoperative staging and histological examination. 


\section{Patients and Methods}

\section{Population}

Between November 2006 and March 2009, study was conducted according to our institution's ethical guidelines and was approved by the melanoma group. Fifteen patients, 7 males, 8 females with a mean age of 56 years (range: 38 to 71 years) were investigated by MRI and FDG-PET for staging of preoperative assessment of liver metastases.

All patients were suspected to present liver metastases following the discovery of one or more lesions on surveillance ultrasound. Overall staging comprising contrast-enhanced chest, abdomen and pelvis CT scan and bone scintigraphy excluded the presence of any extrahepatic metastatic disease.

All patients were operated with the objective of achieving complete surgical resection. Based on recently published retrospective analysis, no patient presented more than four hepatic lesions visible on US and/or CT . 5

MRI and FDG-PET were performed with a mean of 19 days (range: 1-31 days) before surgery.

\section{MRI and image analysis}

Examinations were performed on a 1.5 T MRI machine (Siemens Symphony, Erlangen, Germany) using surface coils. The MR sequences comprised a FSE T2 sequence with short TE and long TE with fat saturation and respiratory gating, followed by breath-hold sequences: gradient echo 2D T1-weighted in-phase and out-of-phase sequences, gradient echo 3D T1weighted sequence before and after gadolinium injection $(0.2 \mathrm{mmol} / \mathrm{kg}$ injected at a rate of 2cc/s followed by flushing with 20cc of saline solution). After gadolinium injection, acquisition was performed on the arterial phase (20 s), portal phase (60 s) and then at the late phase (4 min). Slice thickness was $6 \mathrm{~mm}$ for 2D sequences and $3.80 \mathrm{~mm}$ for the 3D sequence. Metastatic lesions were considered to be typical when they were spontaneously hyperintense on T1 and moderately hyperintense on T2 compared to normal liver and/or when they had a hypervascular appearance on the arterial phase of the dynamic acquisition. In view of the possible variable appearance of hepatic abnormalities, heterogeneous or homogeneous lesions, hypointense on T1, hyperintense on T2 and presenting variable contrast enhancement were also considered to be metastatic lesions. Biliary cysts and angiomas were defined according to the usual MRI criteria. 
MRI examinations were analysed simultaneously by two radiologists experienced in gastrointestinal disease on a PACS station with no knowledge of the results of FDG-PET, but informed about the presence of liver metastases suspected on ultrasound and/or CT. Lesions were counted, localized according to the classification of liver segments of Couinaud and measured according to their largest diameter.

Suspected capsular miliary disease, defined as the presence of at least one $1 \mathrm{~mm}$ lesion at the periphery of the liver, was systematically reported.

\section{FDG-PET and image analysis}

Examinations were performed on a Gemini GXL PET/CT (Philips Medical Systems, Cleveland, USA) composed of 16-row multi-slice CT scan. The usual acquisition protocol was used. The patient remained fasting for at least 6 hours and capillary blood glucose was measured before intravenous FDG injection. The activity injected was $5 \mathrm{MBq} / \mathrm{kg}$, limited to $550 \mathrm{MBq}$ per patient. The subject remained supine and silent in a quiet, dimly lit room. Acquisition in 3D mode started one hour after injection. The whole body acquisition extended from the base of the skull to the middle of the thighs. Each acquisition step comprised 18.5 $\mathrm{cm}$, i.e. a total of 8 to 12 steps depending on the patient's height. The total acquisition time ranged from 16 to 24 minutes. Reconstruction used was OSEM (ordered subset expectation maximization) iterative technique (2 iterations and 32 subsets). Reconstructed slice thickness was $4 \mathrm{~mm}$.

Attenuation correction was performed by reconstructed CT scans with a slice thickness of 5 mm $(120 \mathrm{kV}, 120 \mathrm{mAs}$, tube rotation time: $0.5 \mathrm{~s}$, pitch: 0.9). CT was performed without breath-holding and without injection of iodinated contrast agent. Interpretation was done on a work station by an experienced nuclear medicine physician analysing simultaneously non attenuation-corrected and attenuation-corrected PET images. All focal zones of significantly increased FDG uptake in the hepatic parenchyma were considered to be pathological after the visualisation in three perpendicular planes. Due to possible variations and the absence of standardization, quantification using standard uptake value (SUV) in focal abnormalities was not used as a discriminant criterion. Some significant extrahepatic abnormalities were also reported. Examinations were interpreted with knowledge of the presence of suspicious hepatic abnormalities on US and/or liver CT. 


\section{Surgical procedure}

All patients were operated in order to achieve R0 resection. Lesions were counted by inspection and palpation of the liver with knowledge of preoperative imaging examinations. Intraoperative US was systematically performed. Lesions were localized in hepatic segments according to the classification of Couinaud.

All lesions detected intraoperatively were resected and submitted to histological examination. Pigmented capsular (miliary) lesions were localized, their dimensions were measured and localized miliary lesions were resected and diffuse miliary lesions (< 10 grains) were destroyed by electrocoagulation.

\section{Statistics}

Sensitivity and positive predictive value were calculated for MRI and FDG-PET compared to surgery by analysing lesion by lesion correlations. The two imaging modalities were compared by a McNemar test. A p value less than 0.05 was considered to be significant. 


\section{Results}

\section{Surgical exploration}

A total of 28 lesions were resected in 12 of the 15 operated patients. The number of lesions resected ranged between 1 and 6, i.e. a mean of 2 lesions per patient. All resected lesions corresponded histologically to metastases from uveal melanoma except for one lesion corresponding to an eosinophil abscess. Resection was considered to be R0 for these 12 patients.

Nine of the 27 metastatic lesions resected were smaller than $5 \mathrm{~mm}, 7$ measured between 5 and $10 \mathrm{~mm}$ and 11 were larger than $10 \mathrm{~mm}$.

For 3 patients, multiple $1 \mathrm{~mm}$ pigmented capsular grains (more than 10) corresponding to diffuse miliary metastatic disease excluded the possibility of complete resection (macroscopically incomplete $\mathrm{R} 2$ resection). In two cases, miliary disease was the only manifestation of the disease and was suspected on preoperative MRI (Figure 1). Miliary disease was associated with a $1 \mathrm{~cm}$ nodular lesion in one case.

Lesion by lesion analysis between imaging modalities and operative and histological results was based on only 12 patients with R0 resection.

\section{Lesion by lesion analysis}

MRI and FDG-PET were concordant in only 7 out of 12 patients. A single $18 \mathrm{~mm}$ lesion correctly diagnosed by MRI was not detected by FDG-PET. Three other $1 \mathrm{~cm}$ lesions in the same patient, visible on MRI, were not detected on FDG-PET. For other three patients, MRI showed additional lesions not detected on FDG-PET (Figure 2). For 11 of the 18 lesions detected, MRI showed a spontaneous hyperintense signal on T1-weighted sequences.

The results of lesion by lesion analysis are reported in Table 1. No false-positive was observed for FDG-PET scan versus one false-positive for MRI. The sensitivity was $67 \%$ for MRI and 45\% for FDG-PET. The positive predictive value was 95\% for MRI and 100\% for FDG-PET.

Comparison of the two methods for histologically confirmed metastases $(n=27)$ is reported in Table 2. MRI was found to be superior to FDG-PET ( $p=0.01$; McNemar test). 


\section{Effect related to the size of the lesions}

Analysis according to the size of the lesions is reported in Table 3.

All lesions not detected by MRI corresponded to pigmented capsular lesions measuring 1 to 2 $\mathrm{mm}$. The lesions not detected by FDG-PET, apart from capsular lesions, consisted of 5 intraparenchymal nodules measuring between 5 and $10 \mathrm{~mm}$ and two nodules larger than 10 mm. These lesions were situated in segment VII $(n=2)$, segment VIII $(n=2)$, and one lesion in each of segments I, IV and V. The sensitivity for lesions greater than or equal to $5 \mathrm{~mm}$ was therefore $100 \%$ for MRI versus $61 \%$ for FDG-PET.

\section{Presence of extrahepatic lesions}

FDG-PET detected a suspicious zone of focal uptake in the right deltopectoral region in one patient. Clinical interview, physical examination and ultrasound diagnosed a muscle tear. 


\section{Discussion}

\section{Methodological aspects of the study and PET study}

In our institution, the metastatic work-up in patients suffering from uveal melanoma consists of total body CT, bone scintigraphy, liver MRI. The aim of this study was to compare the performances of the last versus FDG-PET scan. For this reason we decided to add to the metastatic work-up metabolic imaging by PET scan.

The subset of patients in this study presents a highly selected group because of the surgical indications limiting number of detected metastasis less than five. ${ }^{5}$ In all 15 patients only hepatic metastasis had been detected, and no case of extrahepatic metastatic lesion was found. Performance of FDG-PET imaging is limited by numerous technical and methodological factors. Firstly, spatial resolution is insufficient to detect subcentimetric lesions due to partial volume effect. It is more difficult to detect even metabolically active lesions if their size is less than $1 \mathrm{~cm}$. Secondly, FDG uptake reflects glucose metabolic rates, which is physiologically present in normal liver. Thus, the normal "mottled" background is an other factor which decreases the sensitivity of liver lesion detection and the target to background ratio. Lesions that are quite large may not be detected if their metabolism matches the patient's one.

The last very important limitation in metabolic imaging is the respiratory motion producing localisation and reconstruction artefacts. Therefore respiratory gating techniques, mainly used in chest pathologies, should possibly improve the results.

\section{FDG-PET versus MRI imaging}

This preliminary study shows that MRI is superior to FDG-PET for preoperative staging of liver metastases from uveal melanoma including for lesions larger than $5 \mathrm{~mm}$.

This result can be largely explained by differences of spatial resolution between FDG-PET and MRI and probably by the non-avid FDG lesions preventing their discrimination from normal hepatic parenchyma. The sensitivity of FDG-PET detection of liver metastases of $45 \%$ is one of the lowest rates reported in the literature, but is nevertheless equivalent to that reported by Ghanem concerning liver metastases from cutaneous melanoma, with a sensitivity of FDG-PET of $47 \% .{ }^{10}$ In a recent review, Rappeport reported sensitivities of FDG-PET for the detection of liver metastases from colorectal cancers between 65 and 87\%. ${ }^{14}$ Three of these studies reported a particularly low detection rate for lesions smaller than $1 \mathrm{~cm} .{ }^{15-17}$ The 
same author reported a sensitivity of 54\% for FDG-PET in a lesion by lesion analysis of liver metastases from operated colorectal cancer. ${ }^{18}$

Although the spatial resolution of FDG-PET is limited compared to that of other imaging modalities, a number of technical aspects could increase the sensitivity of detection. Attenuation correction errors caused by partial volume effect and artefacts related to liver movements essentially breathing, are probably partly responsible for the decreased contrast between lesions and normal liver mostly at the lung/liver interface. In our study, 4/7 of lesions larger than $5 \mathrm{~mm}$ not visible on FDG-PET were located in segments of the hepatic dome (segments VII and VIII).

Finally, some studies suggest that uveal melanoma has a variable glucose metabolism and that tracers studying other metabolic pathways such as methionine labelled by carbon 11 [11-C] or fluorine 18 [F-18] labelled FDOPA would be more useful in this diagnosis. ${ }^{19-21}$

The global sensitivity of MRI of $67 \%$ also appears to be disappointing. In the same review by Rappeport the global sensitivity of detection of liver metastases from colorectal cancers ranged between 70 and 98\%. ${ }^{14}$ Reported sensitivities nevertheless vary considerably according to the size of the lesions. The lowest sensitivity in the series reported by Ward (22) comprised 39\% of metastatic lesions from colon cancer less than or equal to $1 \mathrm{~cm}$. ${ }^{22}$ Our series comprised $59 \%$ of lesions less than or equal to $1 \mathrm{~cm}$. Reported sensitivities of MRI for lesions larger than $1 \mathrm{~cm}$ ranged between $92 \%$ and 100\%, as in our series in which the sensitivity was $100 \%$.

In our experience, T1-weighted sequences and sequences at the arterial phase of dynamic acquisition after injection of a gadolinium chelate are the most effective for detection of metastatic lesions from uveal melanoma and T2-weighted sequences appear to be more useful for differential diagnosis. Diffusion-weighted sequences and the use of liver-specific contrast agents (SPIO) have yet to be evaluated in this setting.

\section{Miliary disease}

From a surgical point of view, apart from counting individual lesions, it appears particularly useful to be able to predict the presence or absence of capsular miliary disease. Miliary disease was present in 3 out of 15 patients in the present series. In two patients, miliary disease was suspected on MRI due to the presence of at least one capsular lesion. Miliary disease was never suspected on FDG-PET. 


\section{Conclusion}

In this preliminary series, we showed that MRI was superior to FDG-PET for the staging of liver metastases from uveal melanoma. This difference was particularly marked for lesions measuring less than $10 \mathrm{~mm}$. Although MRI has a poor sensitivity for the detection of lesions smaller than $5 \mathrm{~mm}$, it appears to be the only imaging modality sometimes able to suggest the presence of miliary metastatic disease. It is important to detect this particular form of metastases, as it compromises $\mathrm{R} 0$ resection and justifies the choice of another nonsurgical treatment.

Conflict of interest : The authors have no conflict of interest 


\section{References}

1. Vidal JL, Bacin, F, Albuisson E, et al. Epidemiological study of uveal melanoma in France. J. Fr. Ophtalmol. 1995;18:520-8.

2. Desjardins L, Dorval T, Levy C, et al. Etude randomisée de chimiothérapie adjuvante par le deticène dans le mélanome choroïdien. Ophtalmologie 1998;12:168-173.

3. Zografos . Tumeurs intraoculaires, 2002, ed Masson:212-29.

4. Salmon RJ, Levy C, Plancher C, et al. Treatment of liver metastases from uveal melanoma by combined surgery-chemotherapy. Eur J Surg Oncol. 1998;24:127-30.

5. Mariani P, Piperno-Neumann S, Servois V, et al. Surgical management of liver metastases from uveal melanoma: 16 years’ experience at the Institut Curie. Eur J Surg Oncol 2009;27[Epub ahead of print]

6. Semelka R, Martin D, Balci C, et al. Comparison of dual-phase CT and multisequence multiplanar MR imaging including dynamic gadolinium enhancement. J Magn Reson Imaging 2001;13:397-401.

7. Prenikumar A, Marincola F, Taubenberger J, Chow C, Venzon D, Schwartzentruher D. Metastatic melanoma: correlation of MRI characteristics and histopathology. J Magn Res Imaging 1996;1:190-4.

8. Meli RJ, Ros PR. MR appearance of intra-abdominal metastatic melanoma. Magn Res Imaging 1992;10:705-8.

9. Holder W, White R, Zuger J, Easton J, Greene F. Effectiveness of PET for detection of melanoma metastases. Ann Surg 1998;227:764-71.

10. Ghanem N, Altehoefer C, Högerie S, et al. Detectability of liver metastases in malignant melanoma: prospective comparison of MRI and PET. Eur J Radiol 2005;54:264-70.

11. Finger P, Kurli M, Reddy S, Tena L, Pavlick A. Whole body PET/CT for initial staging of choroidal melanoma. Br J Ophtalmol 2005;89:1270-74.

12. Kurli M, Reddy S, Tena L, Pavlick A, Finger P. Whole body PET/CT staging of metastatic choroidal melanoma. Am J Ophtalmol 2005;140:193-9.

13. Francken A, Fulham M, Millward M, Thompson J. Detection of metastatic disease in patients with uveal melanoma using PET. Eur J Surg Oncol 2006;32:780-4.

14. Rappeport E, Loft A. Liver metastases from colorectal cancer: imaging with superparamagnetic iron oxide (SPIO)-enhanced MR imaging, CT and PET. Abdom Imaging 2007;32:624-34.

15. Ruers T, Langenhoff B, Neelman N, et al. Value of PET with FDG in patients with colorectal liver metastases: a prospective study. J Clin Oncol 2002;20:388-95. 
16. Fong Y, Saldinger P, Akhurst T, et al. Utility of FDG-PET scanning on selection of patients for resection of hepatic colorectal metastases. Am J Surg 1999;178:282-7.

17. Selzner M, Hany T, Wildbrett P, et al. Does the novel PET/CT imaging modality impact on the treatment of patients with colorectal cancer of the liver ? Ann Surg 2004;240:1027-36.

18. Rappeport ED, Loft A, Berthelsen AK, et al. Contrast-enhanced FDG-PET/CT vs. SPIOenhanced MRI vs. FDG-PET vs. CT in patients with liver metastases from colorectal cancer: a prospective study with intraoperative confirmation. Acta Radiol 2007;48:369-78.

19. Lucignani G, Paganeli G, Modorati G, et al. MRI, antibody-guided scintigraphy and glucose metabolism in uveal melanoma. JCAT 1992;16:77-83.

20. Lindholm P, Leskinen S, Nagren K, et al. Carbon11-methionine PET imaging of malignant melanoma. J Nucl Med 1995;36:1806-10.

21. Dimitrakopoulou-Strauss A, Strauss LG, Burger C. Quantitative PET studies in pretreated melanoma patients: a comparison of 6-(18F)fluoro-L-dopa with 18F-FDG and (15)O-water using compartment and noncompartment analysis. J Nucl Med 2001;42:248-56.

22. Ward J, Naik K, Guthrie J, et al. Hepatic lesion detection after superparamagnetic iron oxide enhancement: comparison of five T2-weighted sequences at $1.0 \mathrm{~T}$ by using alternatefree response receiver operating characteristic analyses. Radiology 2000;214:159-66. 
Table 1. Results of MRI and FDG-PET for the detection of liver metastases.

\begin{tabular}{|c|c|c|c|}
\hline \multicolumn{3}{|c|}{ Surgery and histology } \\
\hline \multirow{3}{*}{} & & $\begin{array}{c}\text { Positive } \\
(\mathrm{n}=27)\end{array}$ & $\begin{array}{c}\text { Negative } \\
(\mathrm{n}=1)\end{array}$ \\
\hline \multirow{2}{*}{ MRI } & Positive & 18 & 1 \\
\cline { 2 - 4 } & Negative & 9 & 0 \\
\hline FDG-PET & Positive & 11 & 0 \\
\cline { 2 - 4 } & Negative & 16 & 1 \\
\hline
\end{tabular}


Table 2. Correlation of MRI and FDG-PET for the detection of liver metastases.

\begin{tabular}{|l|c|c|c|c|}
\hline & & \multicolumn{2}{|c|}{ FDG-PET } & \\
\hline & & $\begin{array}{c}\text { Lesions not detected } \\
\text { (negative) }\end{array}$ & $\begin{array}{c}\text { Lesions detected } \\
\text { (positive) }\end{array}$ & \\
\hline MRI & $\begin{array}{c}\text { Lesions not detected } \\
\text { (negative) }\end{array}$ & 9 & 0 & 9 \\
\hline & Lesions detected (positive) & 7 & 11 & 18 \\
\hline & & 16 & 11 & 27 \\
\hline
\end{tabular}


Table 3. Influence of size of the lesions on the number of lesions detected by each technique.

\begin{tabular}{|l|c|c|c|}
\hline \multirow{2}{*}{} & \multicolumn{2}{|c|}{ Metastases detected by } & $\begin{array}{l}\text { Metastases confirmed (surgery } \\
\text { and histology) }\end{array}$ \\
\hline Size of lesions & MRI & FDG-PET & 9 \\
\hline$<5 \mathrm{~mm}$ & 0 & 0 & 7 \\
\hline $5-10 \mathrm{~mm}$ & 7 & 2 & 11 \\
\hline$>10 \mathrm{~mm}$ & 11 & 9 & 27 \\
\hline Total & 18 & 11 & \\
\hline
\end{tabular}




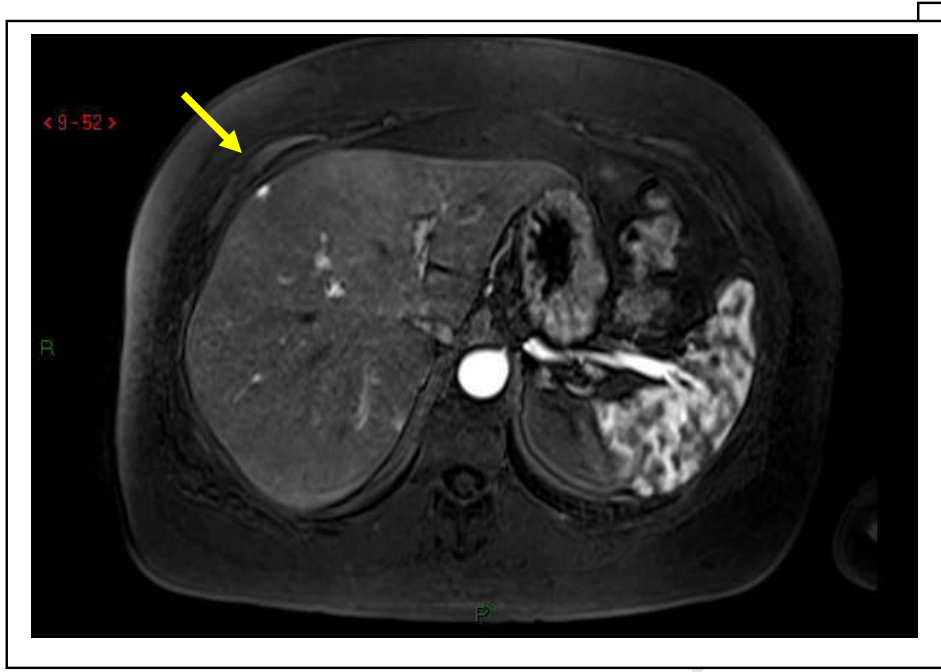

A

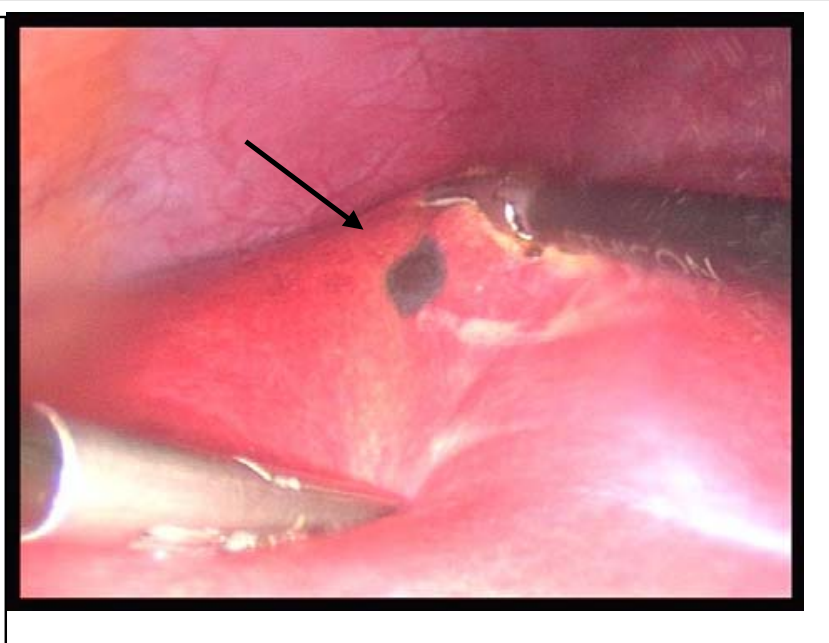

B

Figure 1

1A: Axial 3D T1-weighted sequence, acquisition at the arterial phase. 1B: Corresponding intraoperative laparoscopic view.

Hypervascular capsular lesion of segment IV (arrows) suggestive of capsular miliary disease on MRI. 


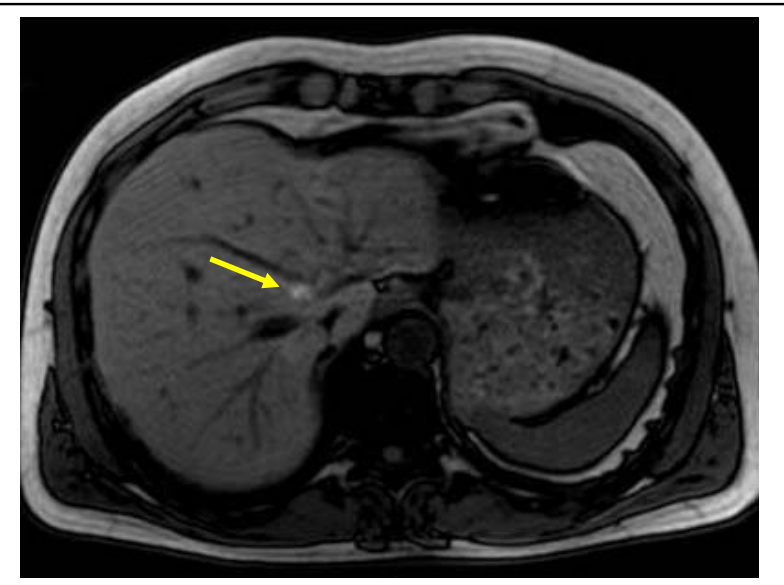

a

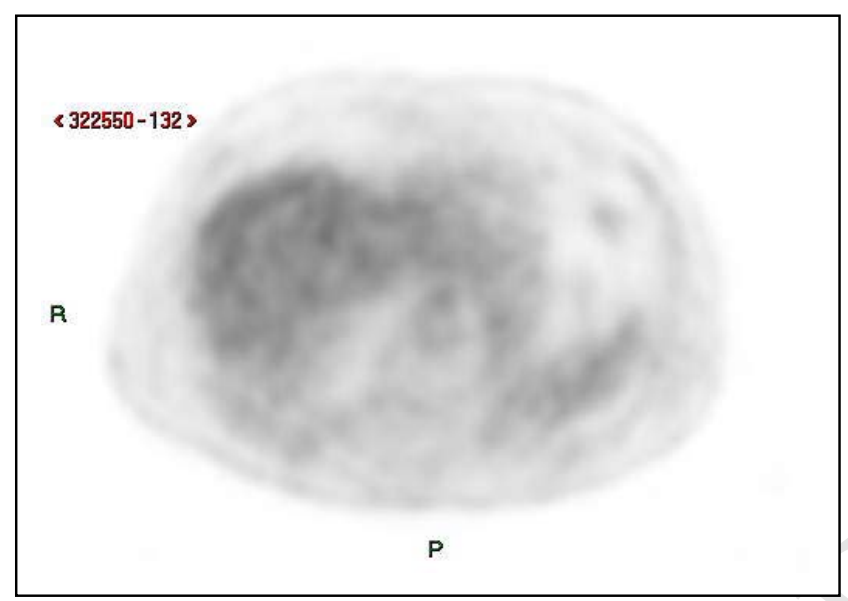

C

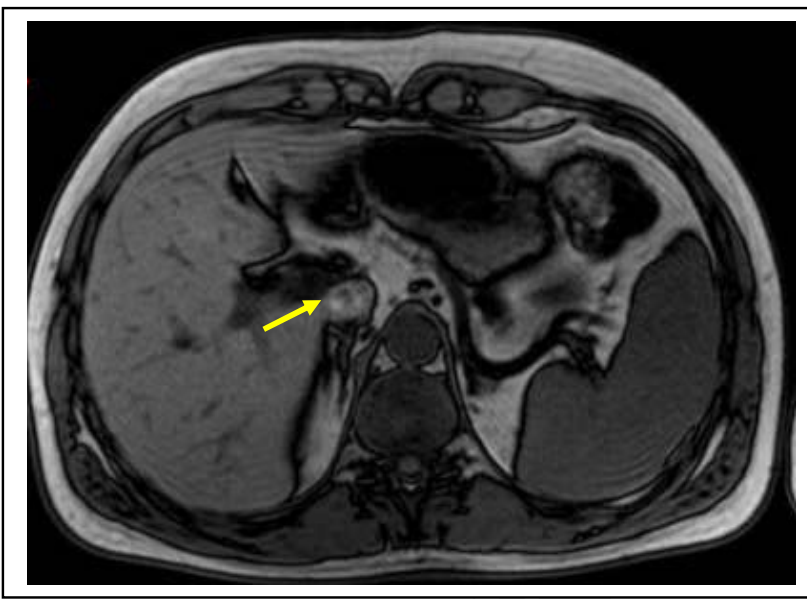

b

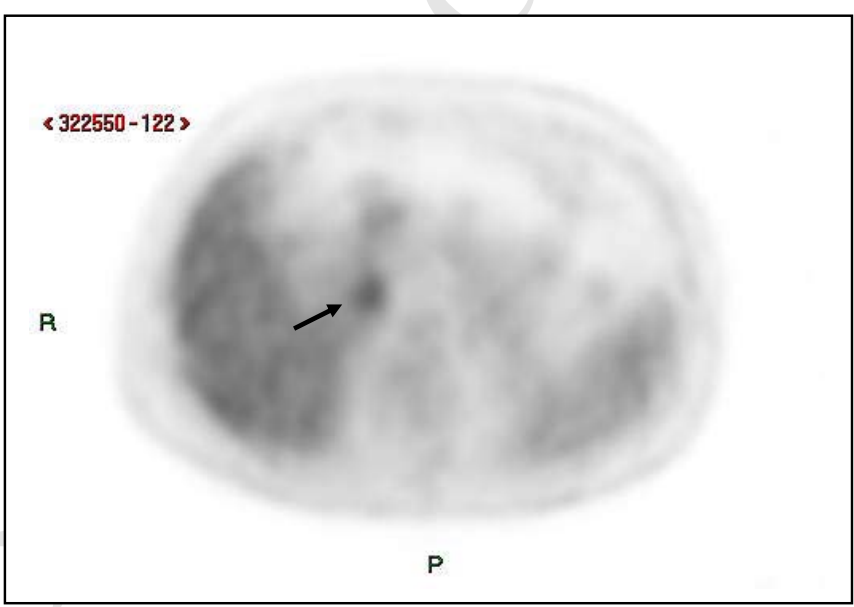

d

Figure 2

2a-b : axial 2D T1 weighted MR slices.

2c-d : corresponding axial 2D attenuation-corrected PET images.

Two lesions with spontaneous hyper intensity are visible in hepatic segments I and VIII (yellow arrows) in the same patient.

PET showed only the supracentimetric one (black arrow in segment I), resulting in a false negative case in segment VIII. 